\title{
A BRINE EVAPORATIVE COOLER/CONCENTRATOR FOR AUTHONOMOUS THERMAL DESALINATION UNITS
}

\author{
A. Cipollina*, G. Micale, L. Rizzuti \\ Dipartimento di Ingegneria Chimica, Gestionale, Informatica, Meccanica, Università di \\ Palermo, Viale delle Scienze, Ed.6, 90128 Palermo (Italy). "E-mail: \\ andrea.cipollina@unipa.it.
}

\begin{abstract}
$\underline{\text { Abstract }}$
In recent years growing attention has been paid to the problem of brine disposal due to the raising awareness of significant environmental issues related to the use of desalination processes for fresh water production. This is particularly relevant when desalination units are located in remote sites, characterised by major complexity in the construction and management of intake and outfall structures.

In the present work a novel device, named Brine Evaporative Cooler/Concentrator (BECC, patent pending), has been developed for coupling with small-scale thermal desalination plants in order to reduce the problem of brine disposal. Such device fulfils two different functions: i) cooling of the recirculating brine (which is often mixed with cold seawater to feed the unit, acting first as a cooling medium for the condensation of the vapour) and ii) concentration of the brine to de disposed.

The BECC device is based on the principle of evaporative cooling, i.e. a primary liquid stream is cooled by means of a secondary liquid stream (by-pass stream), which in turn evaporates in contact with atmospheric air, thus being cooled naturally. The two streams are separated by a heat-conductive surface, through which heat is transferred from the primary stream to the cooling-evaporating by-pass stream.

A lab scale BECC pilot unit has been designed, constructed and tested. Geometrical and operating features have been studied in order to allow the operation with concentrated brines, to minimise problems of corrosion, scaling and fouling. The first results have demonstrated the feasibility of the technology and a larger scale prototype unit has been designed for the installation within a $5 \mathrm{~m}^{3} / \mathrm{d}$ Solar Membrane Distillation unit to be constructed in Pantelleria island (Italy).
\end{abstract}

Keywords: brine disposal, brine recirculation, evaporative cooling, brine cooling, brine concentration 


\section{Introduction}

Today, seawater desalination offers a range of human health, socio-economic, and environmental benefits by providing constant supply of high quality drinking water. Nevertheless, concerns are raised due to potential negative impacts on the environment such as the generation of a concentrate effluent (blow down brine) that must be properly managed. The brine is usually discharged back to the sea by means of purposely designed outfall structures, in some cases consisting in dense effluent diffusers [1], but when such an option is not feasible, due to environmental concerns or to the distance separating the desalination plant from the sea (e.g. for desalination of brackish water from wells in inland sites), reduction of brine volumes is a fundamental goal for the sustainability of the process. Several approaches have been developed for the disposal of desalination brine in the case of inland desalination plants: concentration into solid salts by evaporation ponds, deep-well injection, irrigation of plants tolerant to high salinity (halophytes), and process waste brine minimization.

The use of evaporation ponds for brine disposal has several advantages. These ponds are relatively easy to construct, require low maintenance, no mechanical equipment is required but the pump for moving the brine from the unit to the pond [2]. However they suffer of a huge demand for land and the risk of underground water sources contamination. Therefore, this brine disposal method can be used mainly in the case of desert areas where land cost is very low, evaporation rates high and the risk of underground water contamination is negligible [3].

In order to overtake some of the disadvantages of evaporation ponds Gilron et al. [4] have developed a new process called WAIV (Wind Aided Intensified Evaporation), in which brine evaporates flowing on vertical tissues, with the aid of sun and wind promoting evaporation, thus increasing evaporation rates and decreasing land requirements for brine disposal.

The "deep well injection" technique is applied worldwide for the disposal of industrial wastes and, in recent years, it has been taken into consideration also for the disposal of brine from desalination plants. However many drawbacks characterize this option, such as: the selection of a suitable well site; high costs involved for conditioning the waste brine; possibility of corrosion and subsequent leakage in the well casing; seismic activity which could cause damage to the well and subsequently result in ground water contamination [5], and the large amounts of brine, which usually has to be discharged from desalination plants.

Finally, the use of brine for irrigation of plants tolerant to high salinity may be a feasible option only for small desalination plants and potential applications are limited due to brine temperature (in thermal plants) and chemical additives which may be also present.

In all cases, waste brine volumes minimization is very important and it is usually required for the overall economics of the process. This is generally performed by enhancing the recovery ratio of the desalination processes. In this case, a large portion of the exiting brine is recirculated and mixed with some make-up seawater to feed the unit. Such approach is particularly suitable for thermal processes, where an increase in feed concentration does not affect dramatically the process performances.

However, in many thermal desalination processes, in order to recirculate the brine exiting from the plant, this has to be cooled at a temperature close to seawater temperature (mainly in those processes, in which the cold feed is used also as cooling medium for vapour condensation), which means that a cooling of $5-10^{\circ} \mathrm{C}$ has to be performed (usually from the $40-50^{\circ} \mathrm{C}$ of the exiting brine temperature) in a purposely designed brine cooler.

The cooling of salty solutions is normally performed in heat exchangers made with corrosionresistant materials, but this approach can be used only if a cold stream is available, which is not very likely in remote sites. 
Another possibility is to cool the brine with an open cooling tower. In this case the brine is cooled by evaporation of a small portion of the water itself into atmospheric air, which is therefore humidified. Cooling towers are well known and a lot of studies have been made for increasing their performances. Nevertheless, the disadvantage of this option as a brine cooler is related to the increase in recirculated brine salinity (which means increase in feed salinity) and to the contact of brine with atmospheric air, which generates oxygen (and noncondensable gases) absorption into the recirculated stream, leading, in turn, to the promotion of biological growth in the system, enhancement of corrosion potential of the brine and increase in the non-condensable gases release during the process [6-8]. In order to overtake such drawbacks, devices classified as "indirect cooling towers" or "evaporative coolers" can be used.

Indirect cooling towers perform the cooling of a stream by evaporating a secondary stream and transferring heat from the first to the second (cooled by the evaporation itself) by means of a heat exchange surface separating the two streams. Therefore, these devices usually have two separate fluid circuits. An external circuit (secondary circuit), in which water flows on the outside of the heat exchange surface, which normally is the external surface of a tube bundle, being cooled by the evaporation itself. The second is an internal circuit (primary circuit), in which the main stream flows being cooled by means of heat transfer to the external fluid through the tubes surface [9-12]. Although no practical application of such devices to the case of brine cooling is presented in the literature, tube type coolers may be used for such a purpose, but they would present several significant drawbacks:

- high cost of tubes (anti-corrosion material);

- fouling and scaling on the tubes surfaces (due to rapid salt formation in concentrated brines);

- difficulty in cleaning the tube surface in tube bundle arrangements;

- achievement of a minimum wetting rate (difficult for low brine flow rates).

At the contrary planar geometry would reduce the above drawbacks and would be more suitable for the discussed application. Plate type coolers have already been mentioned in the relevant literature, but only for air cooling purposes [13-14], whereas no examples of plate type geometry evaporative coolers have been presented for the case of brine cooling.

On the basis of the above considerations, in the present work a novel scheme of evaporative cooler with planar geometry has been presented. The system has been developed with the two aims of cooling the brine to be recirculated and concentrating the brine to blow down in order to improve the performance of a thermal desalination plant, achieving a double goal in the same device.

Moreover, the presented device with planar geometry offers the advantages of: 1) extreme geometrical simplicity; 2) use of non expensive and corrosion resistant polymeric materials, which also inhibit scale formation; 3) ease of assembling and disassembling for cleaning operations.

\section{Principles of operation of the BECC device}

The Brine Evaporative Cooler Concentrator (BECC) operating principle is based on the evaporative cooling process (Fig.1), where the cooling of a stream due to its evaporation, is used for the cooling of a second stream separated from the first by a heat transfer surface.

In the BECC device both streams come from a single brine flow. The first, named by-pass brine, flows on the external surface of a polymeric film and is in contact with atmospheric air. 
The evaporation of part of this brine generates its cooling and the cooling of the polymeric surface itself. Moreover the brine is further concentrated due to the evaporation.

The second stream (the main stream constituted by the brine to be recirculated) flows inside the channel generated by the two polymeric films. Thus, this second stream is cooled by heat transfer through the polymeric film to the (colder) by-pass stream.

Looking, in particular, at the heat fluxes and with reference to the Figure 1, the evaporation of a small amount of by-pass brine, along with a possible cooling due to heat transfer to the colder ambient air, generates an exiting heat flux (Q') that subtracts heat to the by-pass brine. At the same time, the main brine stream, being slightly warmer than the cooled by-pass brine, transfers some heat ( $Q$ ') to this latter, by heat exchange through the separation surface between the two streams.

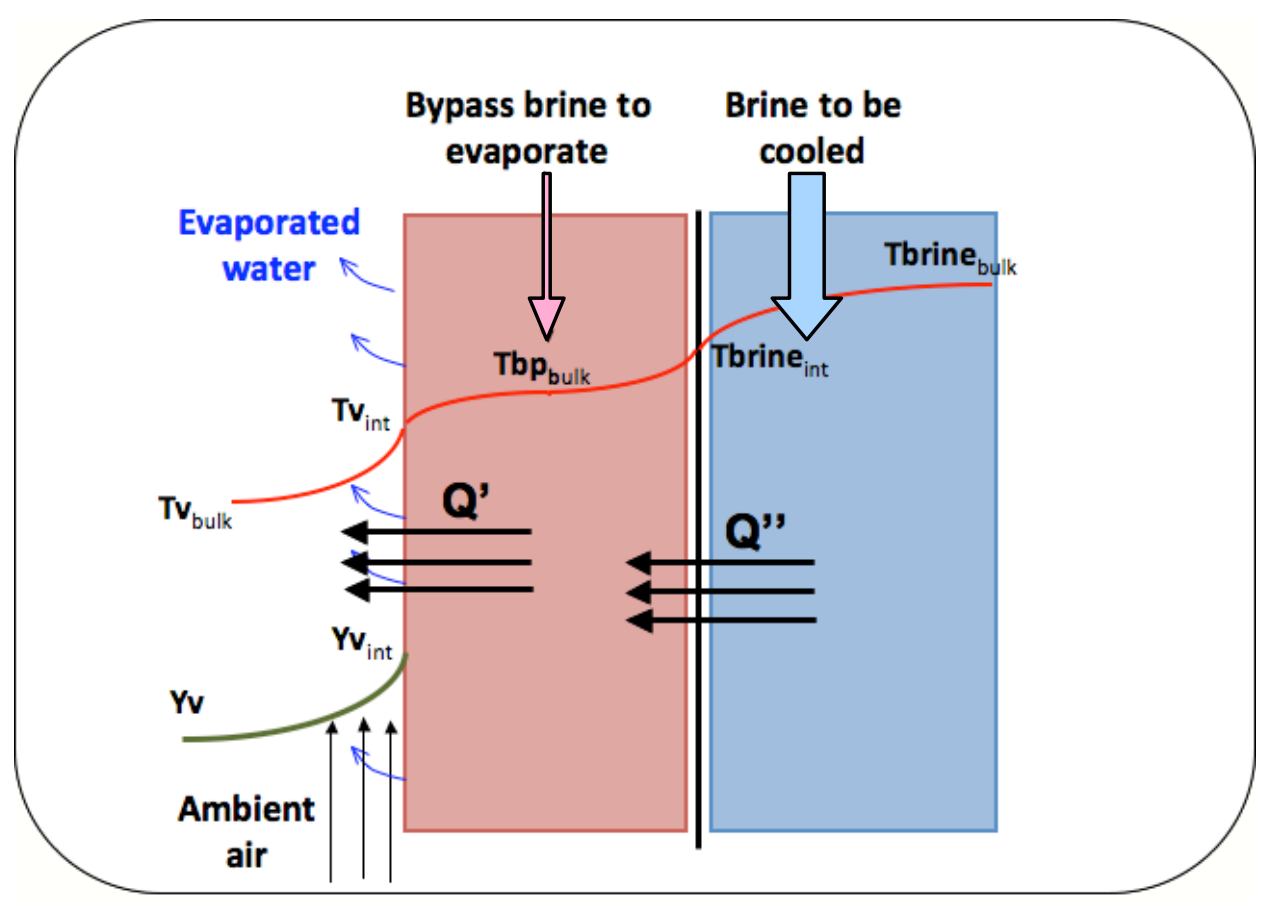

Fig. 1 The evaporative cooling process scheme

Looking at the coupling between the BECC technology and a thermal desalination unit, the main brine stream would be the brine to be re-circulated and used (after being cooled) as a feed to the desalination unit. This brine flows in the internal channel, thus being kept in a closed loop never in contact with atmospheric air.

On the other side, the by-pass brine is the blow-down brine, which is cooled and concentrated (thus reducing its volumetric flow rate) thanks to its evaporation, and then disposed.

In this way, the BECC process provides the two advantages of: 1) reducing the temperature of the re-circulating brine, with no further energy consumption and without changing its physical-chemical properties; 2) reducing the temperature and the quantity of blow-down brine to be disposed, thus reducing the environmental issues related to the desalination process.

A BECC unit (Fig.2) is constituted by thin channels with planar geometry, generated by two layers of thin polymeric film with a polymeric spacer between them. The re-circulated brine flows inside each of these channels, while the by-pass brine flows on their external 
surface, i.e. on the external side of the polymeric film. A gap of few centimetres between subsequent channels allows the passage of atmospheric air, which flows in contact with the by-pass brine, thus generating its evaporation/cooling. A purposely designed feed distributor allows the input of the two streams at the top of the unit. At the outlet (lower part of the unit) the re-circulated brine is collected in an exit channel, whereas the by-pass brine flows down to a tank positioned under the unit.

Such geometry is purposely designed in order to make the system perfectly modular, thus allowing a variable number of channels, from 2-3 up to several tens. This guarantees the system to be able to work with optimal performances at very different operating conditions.

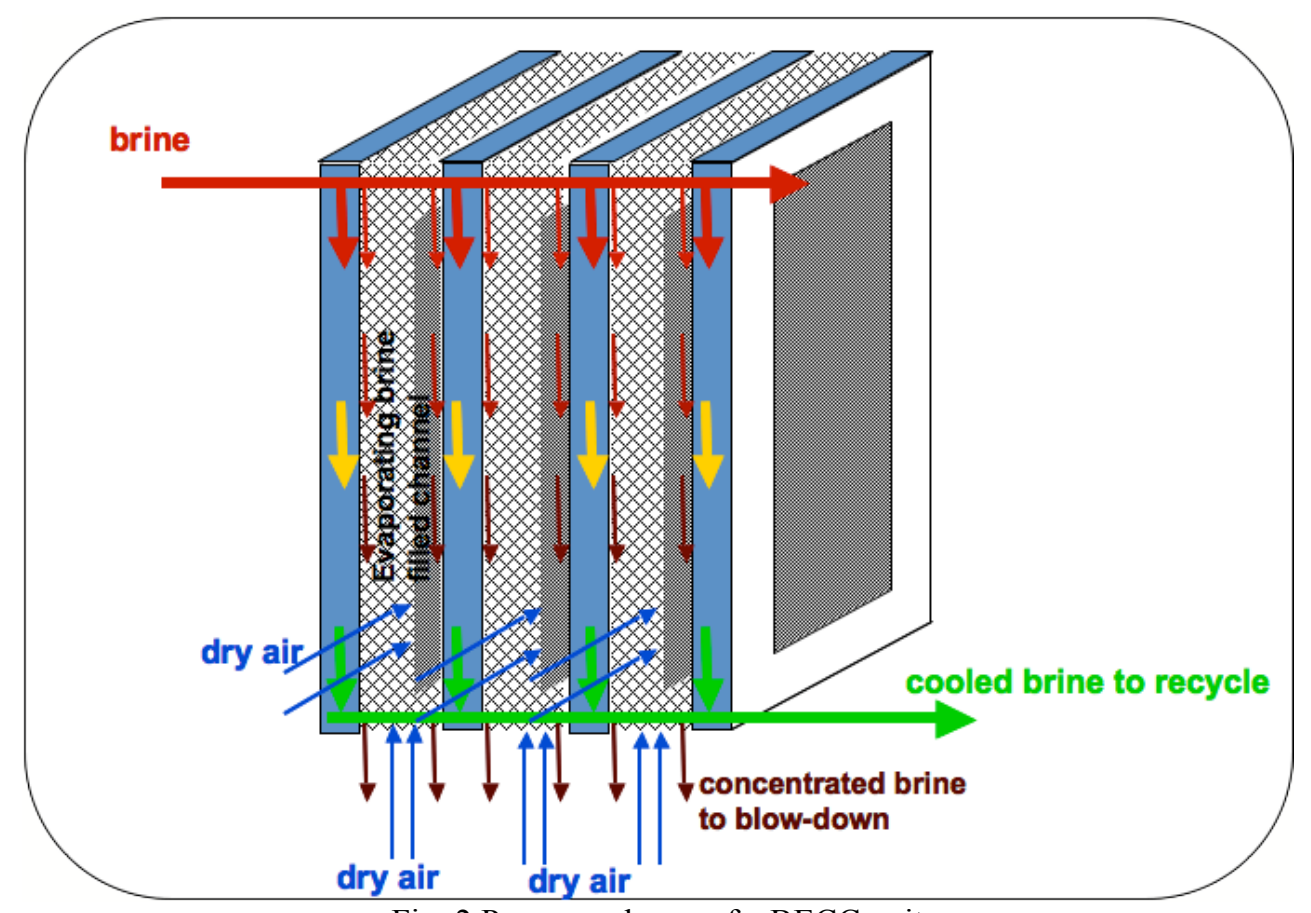

Fig. 2 Process scheme of a BECC unit

As already mentioned in the literature review, the BECC device has been developed focusing on the solution of main drawbacks of conventional brine cooling devices.

In particular, the main innovative aspects of the BECC technology are:

- system modularity, given by the possibility of connecting in parallel several elementary cells (each cell being similar to the one already tested at laboratory scale and shown in the following paragraphs);

- planar geometry, which allows an easy construction, assembling and disassembling of the unit (useful, for example, for periodic cleaning of the surfaces), and which is perfectly appropriate for the system modularity;

- use of polymeric materials, suitable for the use with highly corrosive brine and for scaling liquids (scales usually detaches more easily from polymeric surfaces than from metallic ones);

- use of an inlet feed distributor and surface homogeniser tissue, which allow a very flexible regulation of the evaporating (by-pass) brine flow rate in order to fulfil the requirements for the recirculation ratio of the desalination system. 


\section{Description of the experimental apparatus}

A pilot unit at laboratory scale (with just one elementary cell) has been constructed and tested in laboratory conditions. A sketch of the system is shown in Figure 3. It consisted of two polymeric films (co-polymer Poly Ethylene-TetraFluoroEthylene), supported by two PMMA frames, assembled to generate a thin channel with internal dimensions of $300 \mathrm{~mm}$ (width) x 3 $\mathrm{mm}$ (thickness) x $2000 \mathrm{~mm}$ (height). A spacer with horizontal baffles is inserted inside the channel in order to force the brine to a zig-zag flow with spacer filaments inducing turbulence and enhancing heat transfer.
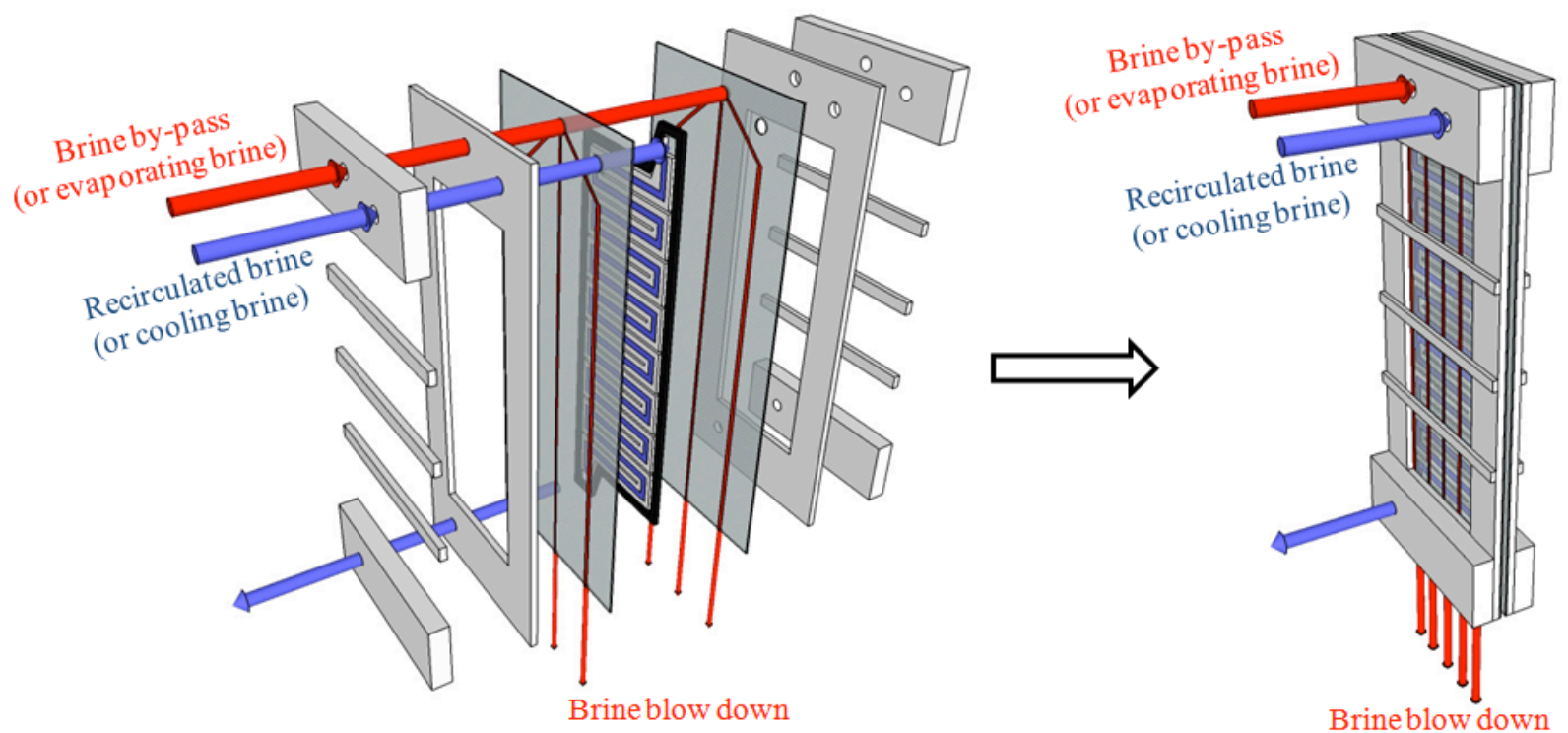

Fig. 3 Sketch of the single cell BECC unit with exploded and assembled views.

A PMMA distributor on the top of the unit (Fig. 4) allows a good distribution of both the internal brine (to be cooled) and the by-pass brine, which then flows externally wetting the two outer surfaces of the polymeric films. Moreover, such surfaces are covered by a thin tissue, which guarantees a uniform distribution of the by-pass brine (notwithstanding the small flow rates) and a good evaporative cooling process performance.

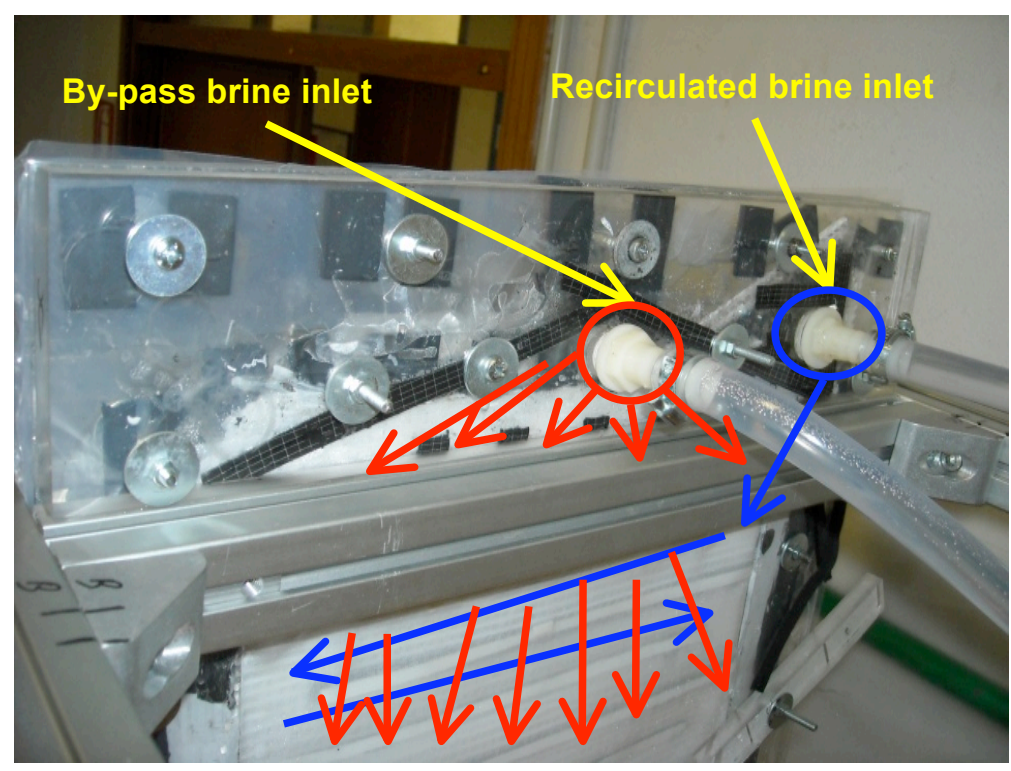

Fig.4 Inlet brine streams distributor 
During the first test runs only fresh water has been adopted instead of brine. This allowed the testing of fluid dynamics and thermal performances of the system, without undergoing scaling problems to be expected when concentrated brines will be treated.

A thermostatic buffer was used to control the temperature of inlet streams and a NI data acquisition system and thermocouples type $\mathrm{T}$ were adopted to monitor temperatures during each run. All the experiments were performed inside the laboratory, where wind was simulated by four fans positioned at about $50 \mathrm{~cm}$ from the central axis of the BECC unit (as shown in Fig. 5), which provided an average air velocity of $2 \mathrm{~m} / \mathrm{s}$.

Ambient air humidity was measured by an analogical hygrometer.
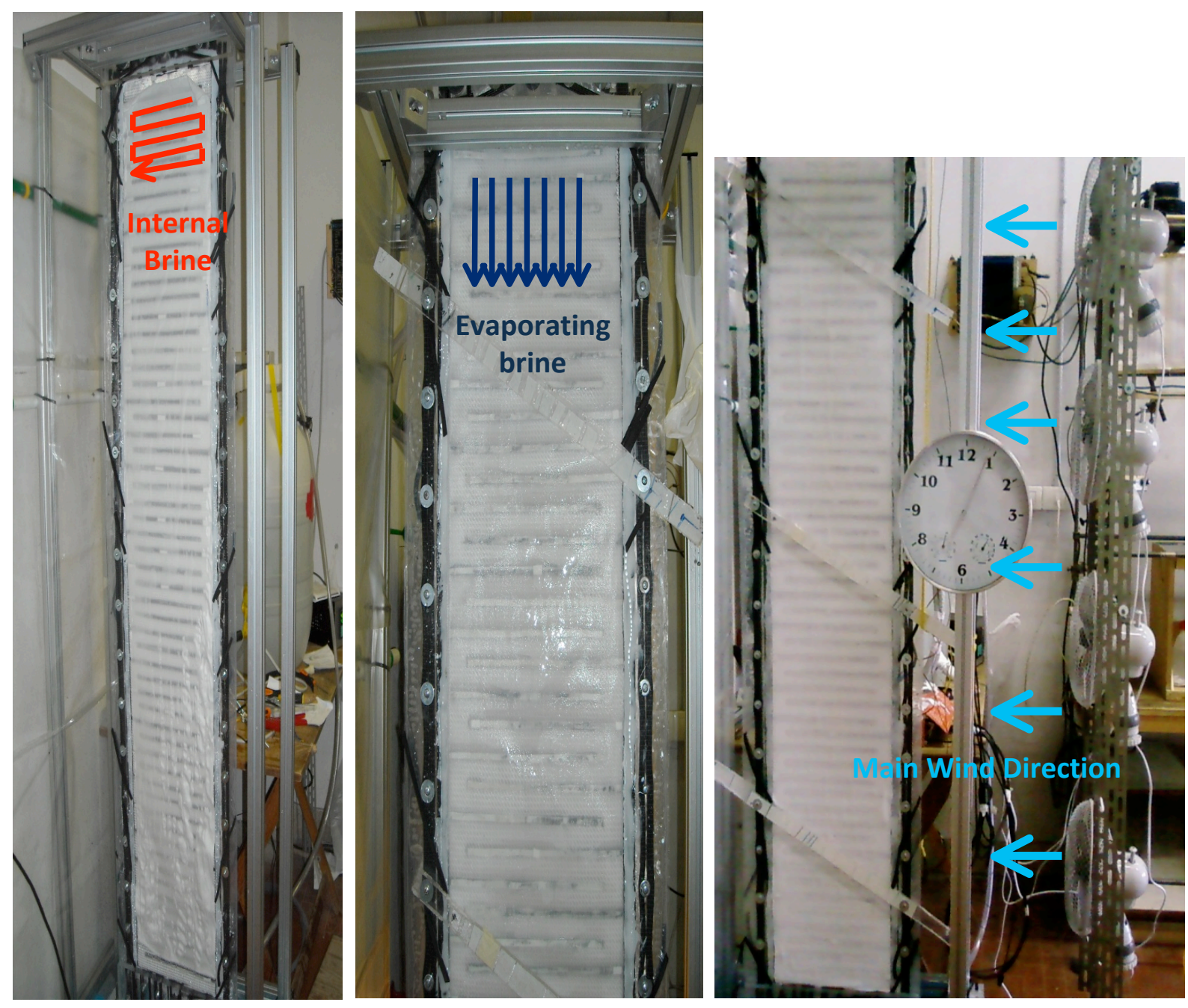

Fig.5 Overviews of the laboratory pilot unit with indications of the flow directions for the two streams and the wind generated by four fans

Experiments were performed pumping hot water from the thermostatic buffer to the two inlets and controlling flow rates by means of two flow meters equipped with shutter valves. Exiting streams were collected in a bottom tank and then re-pumped to the thermostatic buffer, thus closing the circuit. At the end of each day the buffer was refilled in order to provide the water which was removed due to the evaporation. A scheme of the experimental apparatus is reported in Fig. 6. 


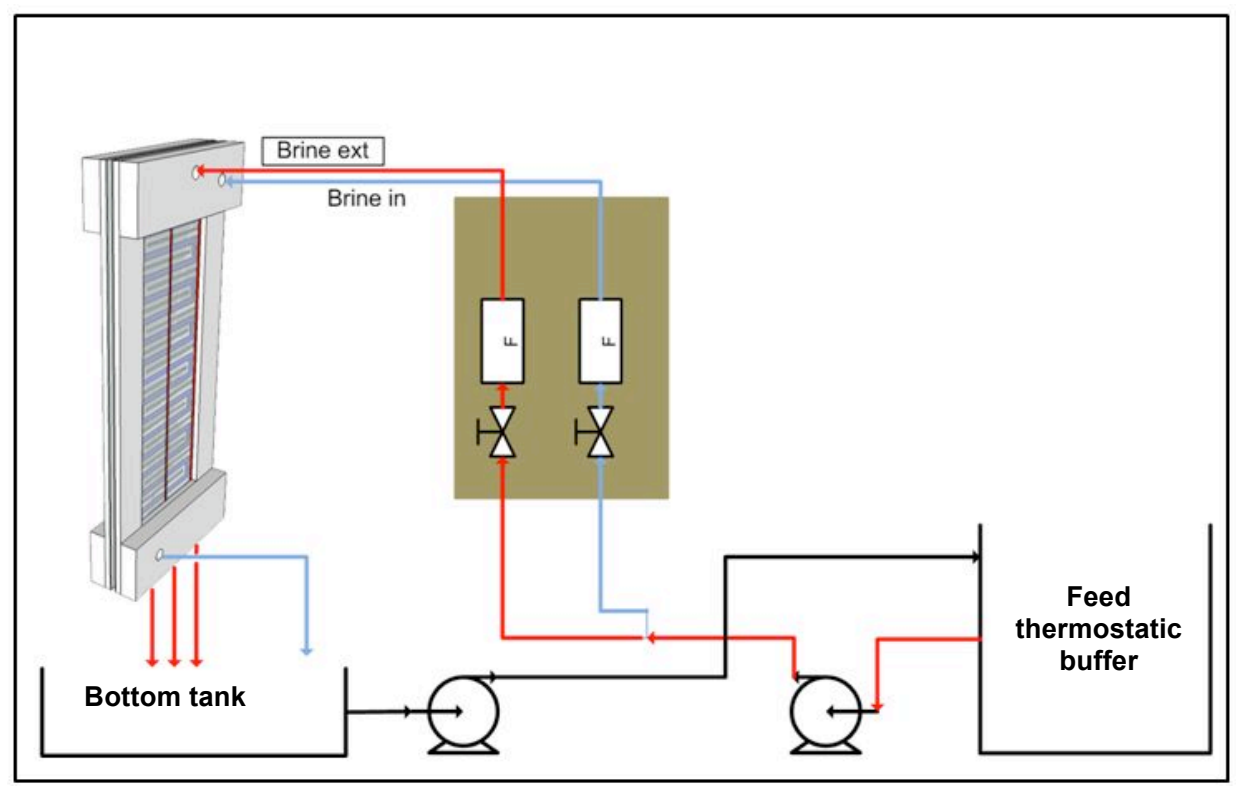

Fig. 6 Scheme of the experimental apparatus used for laboratory tests

\section{Results and discussion}

Laboratory tests were performed in order to collect information on the fluid dynamics and thermal performances of the BECC device. The single cell unit described above was used, while the operating conditions were chosen in order to simulate the use of a BECC system for cooling the recirculated brine of a Membrane Distillation desalination unit, which is presently operating on the island of Pantelleria (Italy). In particular, inlet temperatures ranged between 35 and $50{ }^{\circ} \mathrm{C}$, flow rates varied from 1 to $4 \mathrm{lt} / \mathrm{min}$ for the internal stream and were set to $0,0.3$ and $0.6 \mathrm{lt} / \mathrm{min}$ for the external one.

The ratio $R$ between the two flow rates, defined as:

$$
R=\frac{\text { rec_Brine }}{\text { by-pass_Brine }}
$$

was established taking into account the operating conditions typically assumed in the above mentioned coupling with a MD system (Fig. 8). 


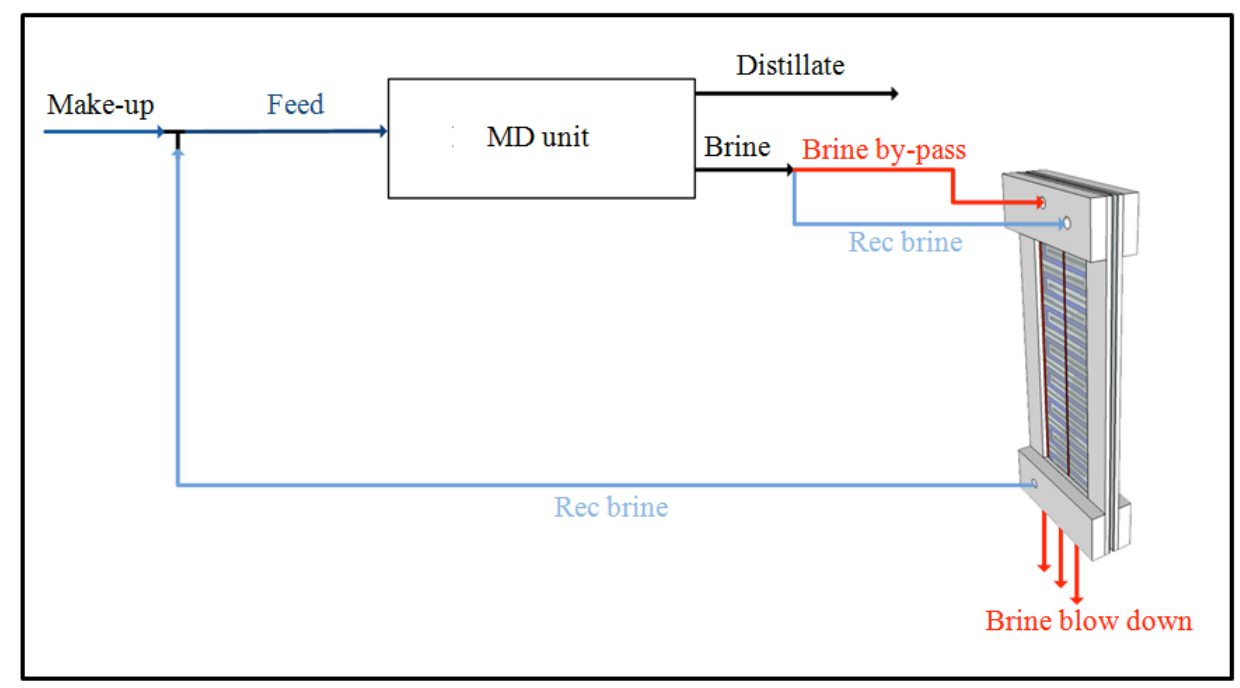

Fig.8 Coupling scheme between a MD unit and the BECC device.

Considering a make-up seawater at $35 \mathrm{gr} / \mathrm{lt}$ concentration, and assuming that recirculated brine is fed to the internal channel while blow down brine is fed to the external channel, simple mass balance equations lead to the operating map reported in Fig. 9. Increasing the feed concentration, also the recirculated brine flow rate can be increased, thus raising the $R$ ratio. On the other side, when the recovery ratio of the MD unit is increased (considering only the "once through" conversion), the concentration of exiting brine rises, thus forcing to a reduction in the recirculated brine and, therefore, in the $R$ ratio.

In typical operating conditions of a seawater desalination MD plant with brine recirculation, feed concentration can vary between 45 and $50 \mathrm{gr} / \mathrm{lt}$, with a MD recovery ratio varying in the range of 6 to $8 \%$ and a rec_Brine to by-pass_Brine ratio typically between 4 and 7 . These values correspond to an internal and external flow rates of $1-21 \mathrm{t} / \mathrm{min}$ and $0.3 \mathrm{lt} / \mathrm{min}$ respectively, or 3-4 $1 \mathrm{t} / \mathrm{min}$ and $0.6 \mathrm{lt} / \mathrm{min}$, in agreement with the above mentioned operating flow rates.

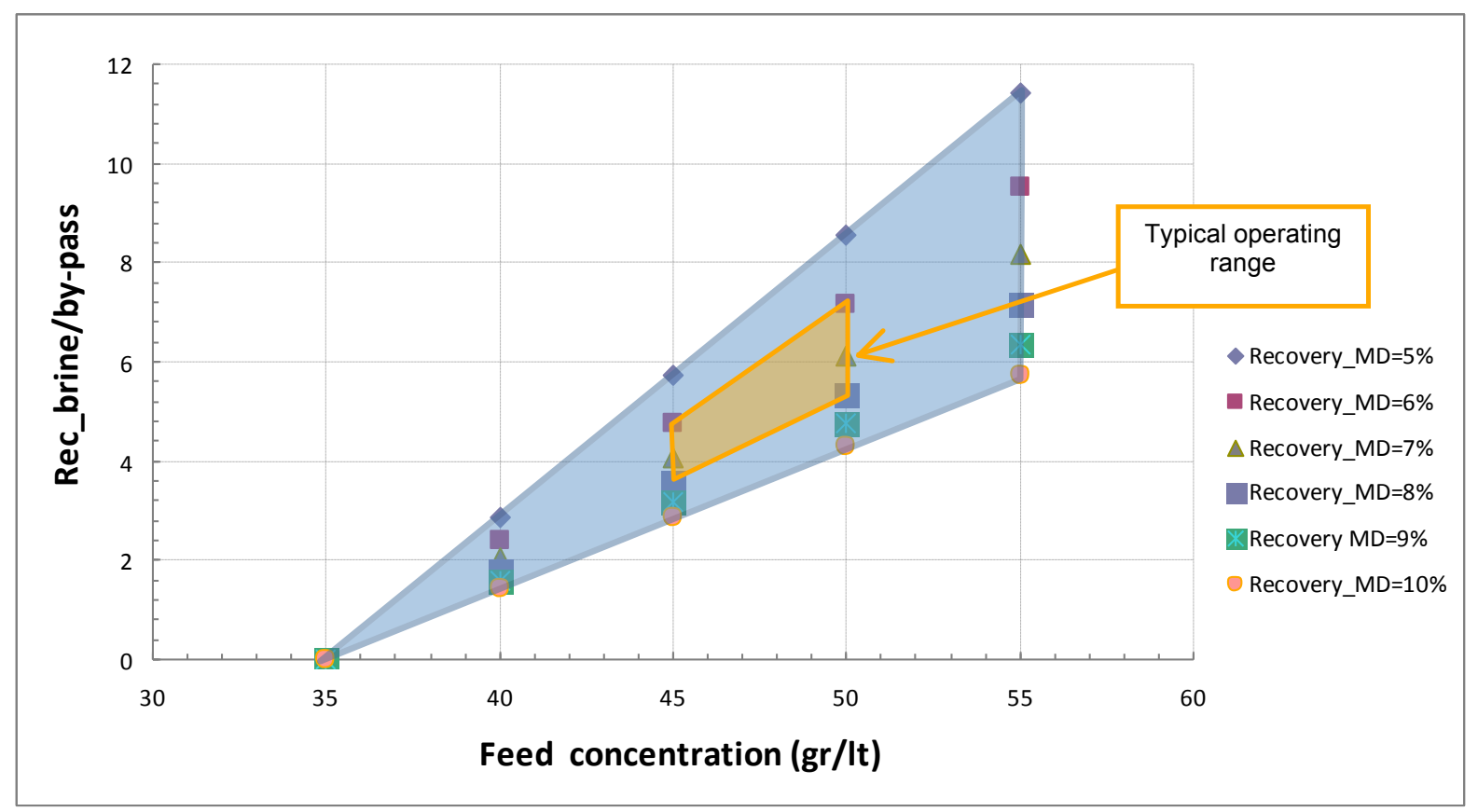

Fig.9 Ratio between internal and external brine streams in a BECC cooler coupled with a MD desalination system as a function of feed concentration and recovery ratio of the MD unit. Typical operating conditions are also highlighted. 
In all experiments ambient conditions were monitored, although no control could be made on ambient temperature and humidity, which varied in the range $22^{\circ} \mathrm{C}-26^{\circ} \mathrm{C}$ and $43 \%-63 \%$ respectively. Wind was generated by four fans, which guaranteed an average horizontal wind velocity of about $2 \mathrm{~m} / \mathrm{s}$.

The performances of the unit were evaluated by analysing the cooling of the two streams with different inlet temperatures and flow rates and by calculating the heat subtracted from the two streams, indirectly estimated by the following equations:

\section{- Heat balance on the internal stream:}

$$
Q_{c b}=F_{c b} C_{p}\left(T_{c b}^{\text {in }}-T_{c b}^{\text {out }}\right)
$$

where $\mathrm{Q}$ is the heat removed, $\mathrm{F}$ is the flow rate, $\mathrm{C}_{\mathrm{p}}$ is the specific heat, $\mathrm{T}^{\mathrm{in}}$ and $\mathrm{T}^{\text {out }}$ are the inlet and outlet temperatures of the stream and the subscript ${ }_{\mathrm{cb}}$ refers to the recirculated brine, i.e. the internal brine to be cooled.

- Heat balance on the external stream:

$$
Q_{e b}=F_{e b} C_{p}\left(T_{e b}^{i n}-T_{e b}^{o u t}\right)
$$

where the subscript ${ }_{\text {eb }}$ refers to the by-pass brine, i.e. the external brine evaporating in contact with ambient air.

- Total heat subtracted:

$$
Q_{t o t}=Q_{c b}+Q_{e b}
$$

\subsection{Temperature reduction in the BECC device}

Figure 10 reports the results, in terms of cooling efficiency as a function of the internal flow rate, of four experiments performed with an inlet temperature of the two streams of about $39^{\circ} \mathrm{C}$ and an external flow rate of $0.3 \mathrm{lt} / \mathrm{min}$. The coloured area gives an indication of the cooling efficiency of the process. The figure shows how at lower internal flow rates lower outlet temperature of the internal stream were registered, thus indicating a better cooling. In particular for the lowest flow rate of $1 \mathrm{lt} / \mathrm{min}$ a cooling of almost $9^{\circ} \mathrm{C}$ is achieved, whereas at $4 \mathrm{tt} / \mathrm{min}$ the cooling is only of about $5^{\circ} \mathrm{C}$. In general, a cooling of $5-8^{\circ} \mathrm{C}$ is required in many thermal desalination processes in order to recirculate the exiting brine, thus the achieved results seem to encourage towards the use of the present device for such purpose. 


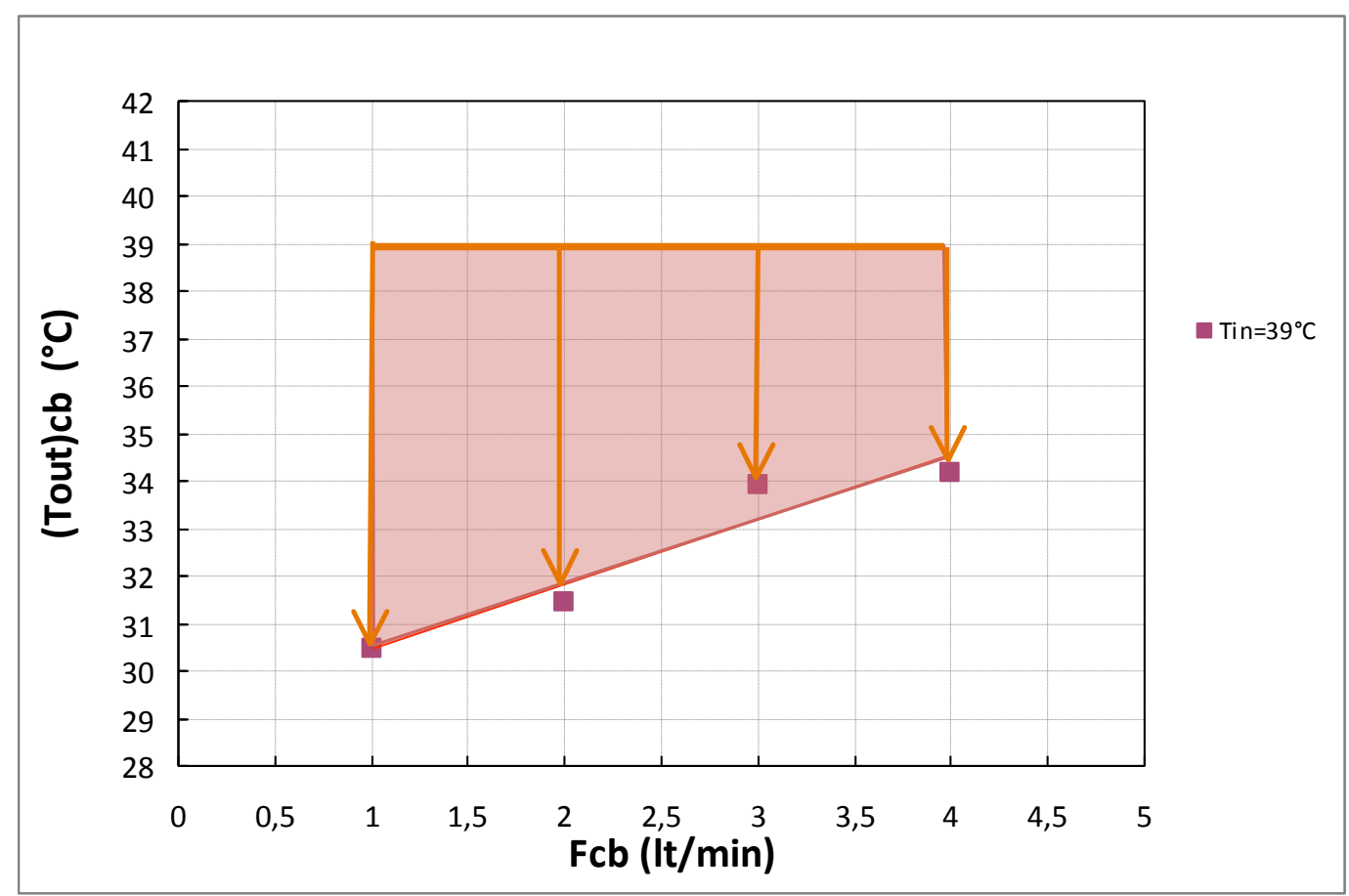

Fig. 10 Cooling efficiency as a function of internal flow rate, with inlet temperature of $39^{\circ} \mathrm{C}$ and an external stream flow rate of $0.3 \mathrm{lt} / \mathrm{min}$.

When the inlet temperature varies also the cooling efficiency is affected, as shown in Fig. 11, where a similar graph to the one just discussed is reported for all the four different inlet temperatures tested during experiments. In particular the higher the inlet temperature the better is the cooling performance, as it was expected due to the increase of the driving force for the heat transfer to the ambient. It is worth noting how for inlet temperature of almost $50^{\circ} \mathrm{C}$ the cooling varies from 7 to $13^{\circ} \mathrm{C}$ at internal flow rates of $41 \mathrm{t} / \mathrm{min}$ and $1 \mathrm{tt} / \mathrm{min}$ respectively. When $\mathrm{T}_{\text {in }}$ is reduced to $44.5^{\circ} \mathrm{C}$, the cooling ranged between $5.5^{\circ} \mathrm{C}$ and $10^{\circ} \mathrm{C}$. While much lower cooling efficiencies are registered for $\mathrm{T}_{\text {in }}=35^{\circ} \mathrm{C}$. 


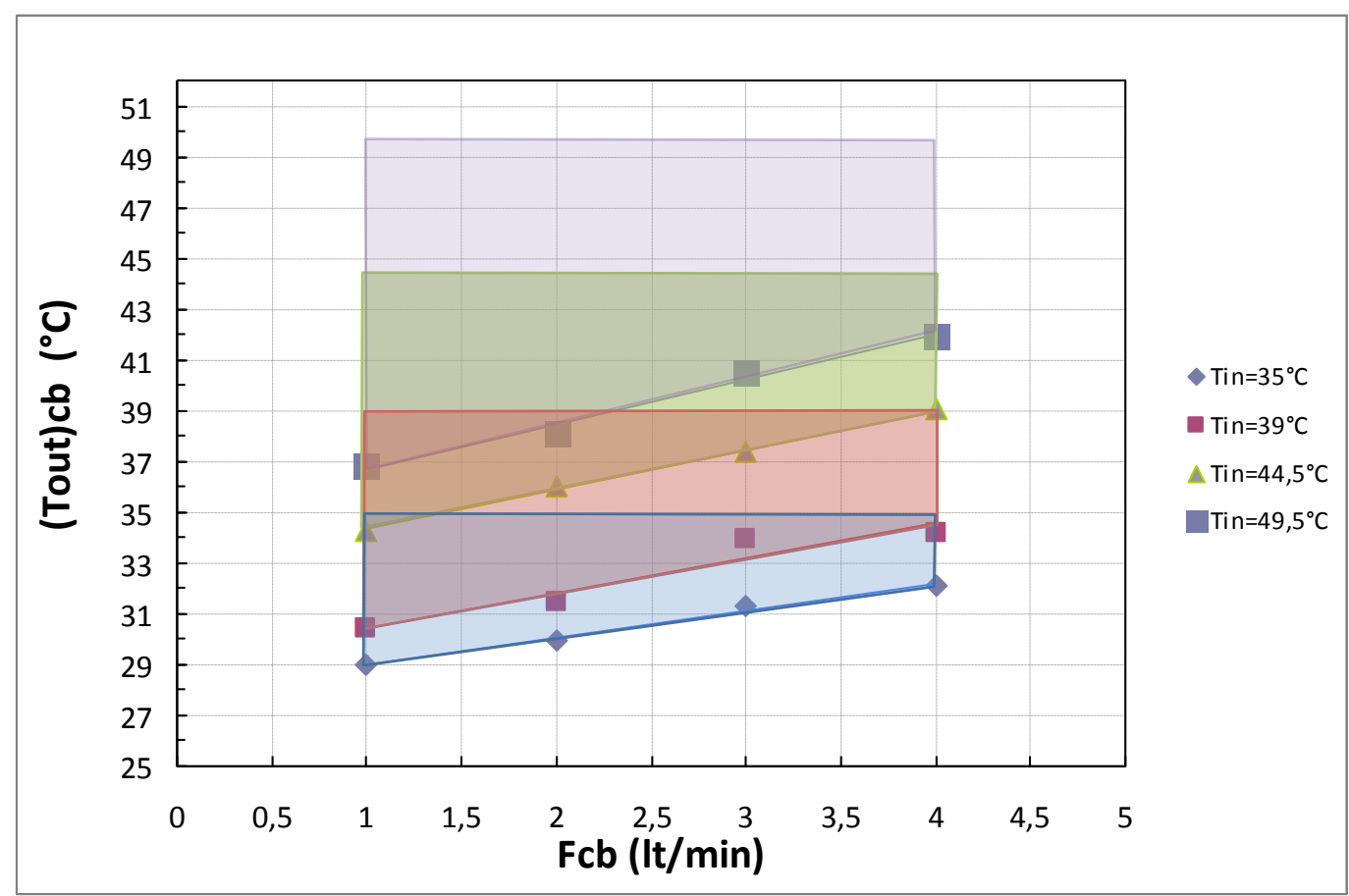

Fig. 11 Cooling efficiency as a function of internal flow rate, with four different inlet temperatures $\left(35^{\circ} \mathrm{C}, 39^{\circ} \mathrm{C}\right.$, $44.5^{\circ} \mathrm{C}$ and $49.5^{\circ} \mathrm{C}$ ) and an external stream flow rate of $0.3 \mathrm{lt} / \mathrm{min}$.

Fig.12 reports similar trends observed with an external flow rate of $0.6 \mathrm{lt} / \mathrm{min}$. Interestingly, results do not change significantly, as the cooling efficiency seems to be similar in the two cases. However, it is observed that starting from the same $\mathrm{T}_{\mathrm{in}}$, the cooling efficiency is slightly reduced by the increase in $F_{e b}$ as will also be outlined in Figs. 14 and 15 .

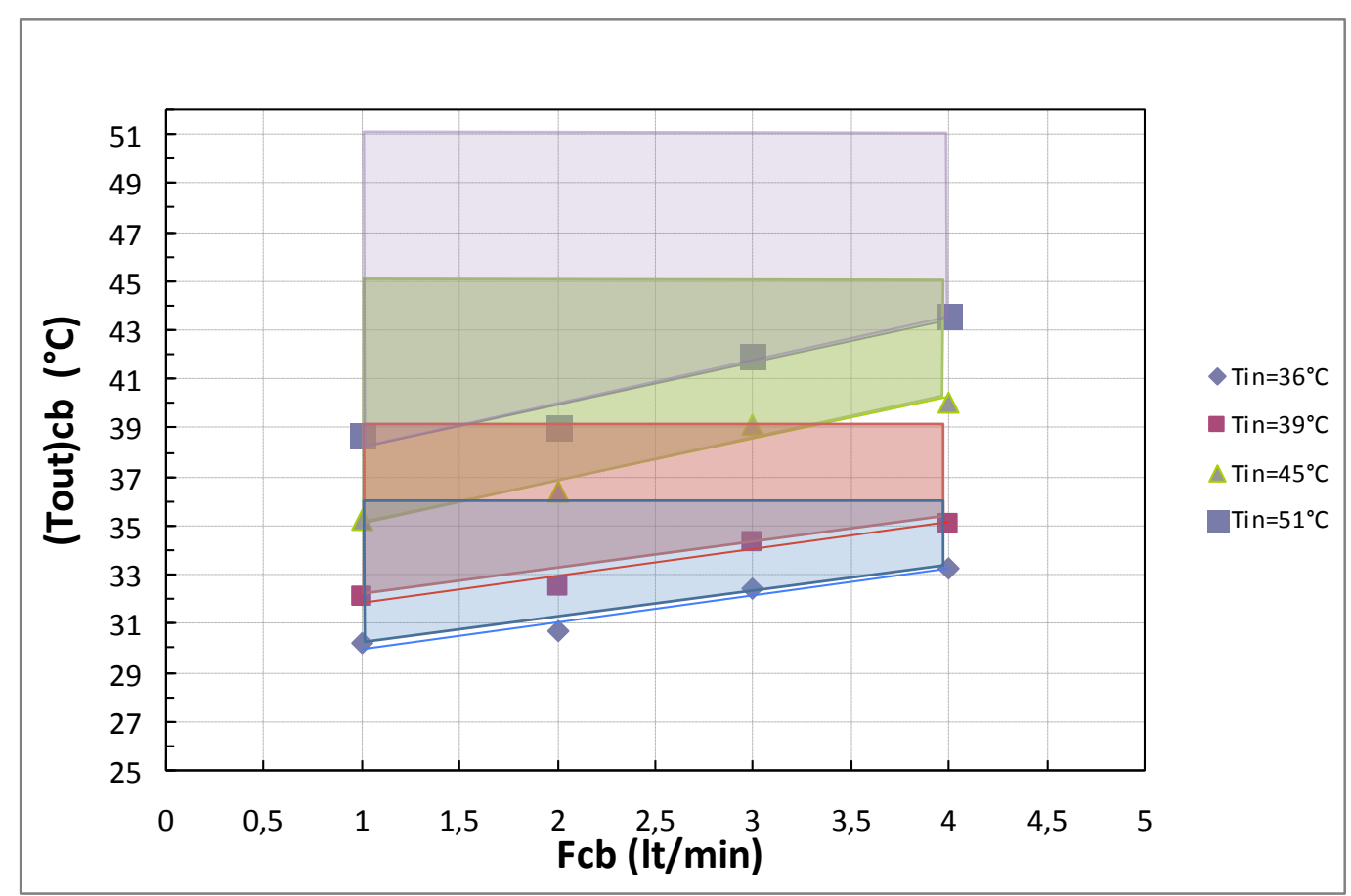

Fig. 12 Cooling efficiency as a function of internal flow rate, with four different inlet temperatures $\left(36^{\circ} \mathrm{C}, 39^{\circ} \mathrm{C}\right.$, $45^{\circ} \mathrm{C}$ and $51^{\circ} \mathrm{C}$ ) and an external stream flow rate $\mathrm{F}_{\mathrm{eb}}=0.6 \mathrm{lt} / \mathrm{min}$. 


\subsection{Cooling heat fluxes in the BECC device}

In figure 13 the rates of heat removal defined in eqs. 2-4 are reported as a function of the average temperature of the fluid in the internal channel, for an internal flow rate $F_{c b}=21 t / m i n$ and the external one $\mathrm{F}_{\mathrm{eb}}=0.3 \mathrm{lt} / \mathrm{min}$. As it is expected, the removed heat significantly increases with the average $T_{c b}$ due to the increase in the driving force for the heat transfer and the evaporation. Interestingly a very large portion of the total heat $\left(\mathrm{Q}_{\mathrm{tot}}\right)$ is due to the cooling of the internal brine $\left(\mathrm{Q}_{\mathrm{cb}}\right)$, thus indicating a good performance of the system, which was also assessed by the quite low temperature differences between the two exiting streams normally registered during the experiments (usually in the range of $1-3^{\circ} \mathrm{C}$ ).

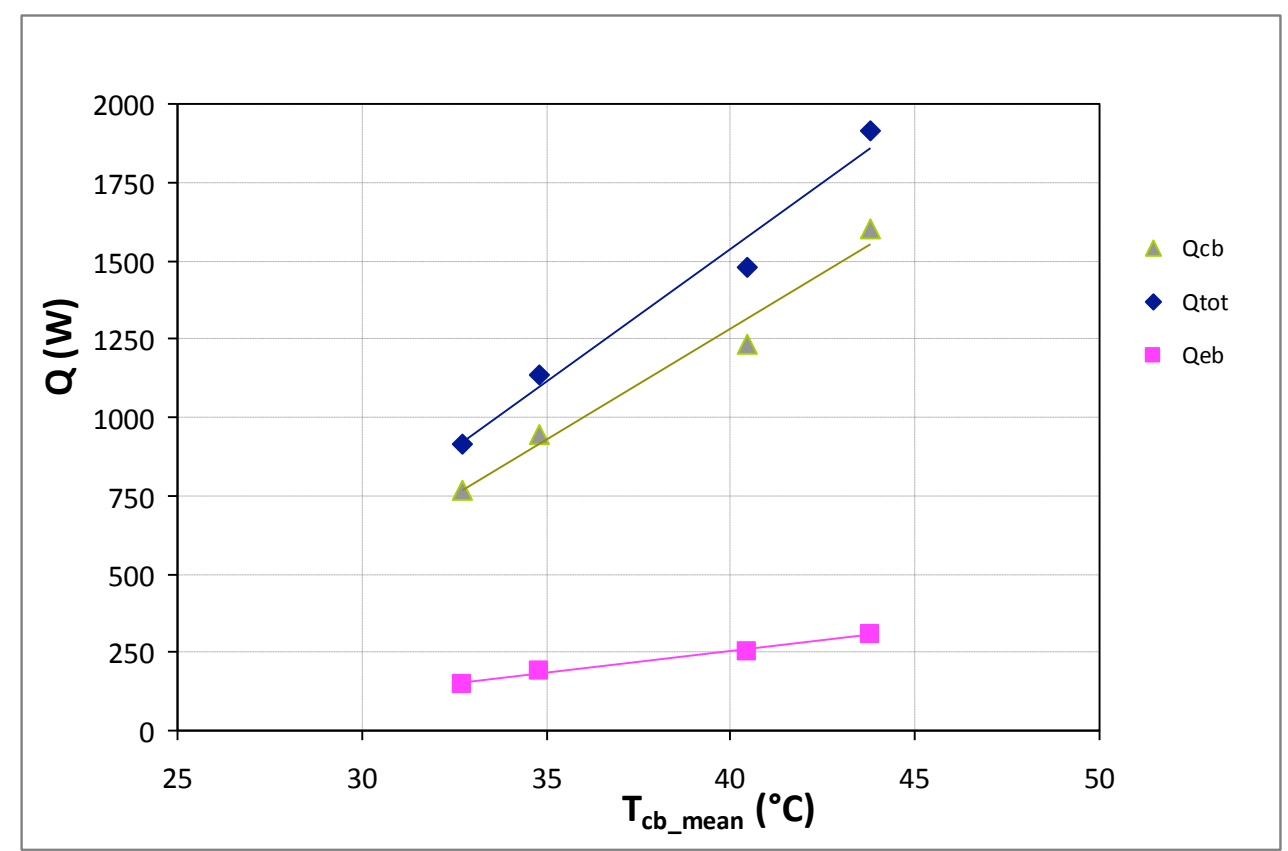

Fig.13 Heat transferred from the internal and external streams to the ambient, as a function of the average temperature of the internal stream. $\mathrm{F}_{\mathrm{cb}}=21 \mathrm{t} / \mathrm{min}$ and $\mathrm{F}_{\mathrm{eb}}=0.3 \mathrm{lt} / \mathrm{min}$.

Similarly, figs. 14 and 15 show the dependence of the heat removal rate from the internal brine as a function of the average internal temperature $\left(\mathrm{T}_{\mathrm{cb}}\right)$ and with internal flow rates $\left(\mathrm{F}_{\mathrm{cb}}\right)$ equal to 1, 2, 3 and $4 \mathrm{lt} / \mathrm{min}$ for the two different external flow rates $F_{\mathrm{eb}}=0.3$ and $0.61 \mathrm{t} / \mathrm{min}$ respectively.

Also in these graphs the increase in the average temperature leads to a significant increase in the heat transferred. In particular the use of the average temperature allows also the comparison of tests performed with different inlet temperatures and flow rates, just comparing the slope shown by the regression lines, notwithstanding the different driving forces due to different cooling efficiencies or inlet temperatures and flow rates. To highlight this fact, in both figures a circle groups the 4 tests characterised by $\mathrm{T}_{\text {in }}$ around $39^{\circ} \mathrm{C}$, indicating how higher $\mathrm{F}_{\mathrm{cb}}$ lead to higher values of average temperature, as it is expected given the lower cooling efficiency already discussed in the previous graphs.

Concerning the dependence on the internal flow rate $F_{c b}$, the two graphs show an important variation of cooling rates passing from $1 \mathrm{lt} / \mathrm{min}$ to $2 \mathrm{lt} / \mathrm{min}$, while for larger flow rates no significant difference has been registered. This has been found in agreement with the experimental evidence that for lower flow rates the fluid dynamic behaviour of the unit was not satisfactory as the zig-zag channels were only partially filled with water (thus wetting only a portion of the entire heat transfer surface available) and velocities were low, thus 
affecting the heat transfer from the internal to the external channel. On the other side, for larger internal flow rates the heat transfer resistance from the internal bulk to the external wetted surface became negligible compared to the resistance related to the evaporation rate and mass/heat transfer from the wetted surface to the ambient air, thus minimising the influence of the internal flow rate on the overall heat transfer coefficient and, therefore, on the cooling rate of the unit $\left(\mathrm{Q}_{\mathrm{cb}}\right)$.

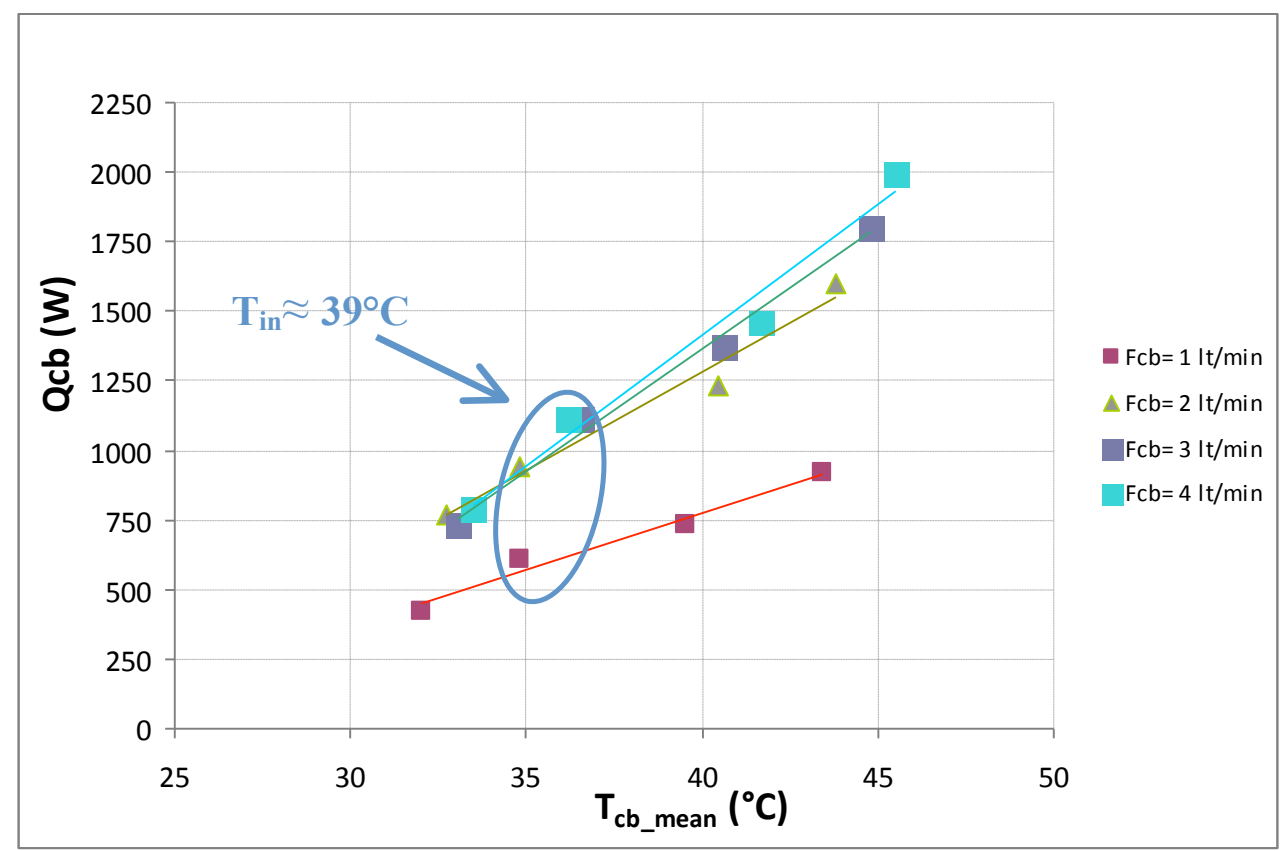

Fig.14 Heat removed from the internal stream, as a function of the average temperature of the internal stream, for different internal flow rates. $\mathrm{F}_{\mathrm{cb}}=1-2-3-4 \mathrm{lt} / \mathrm{min}$ and $\mathrm{F}_{\mathrm{eb}}=0.3 \mathrm{lt} / \mathrm{min}$.

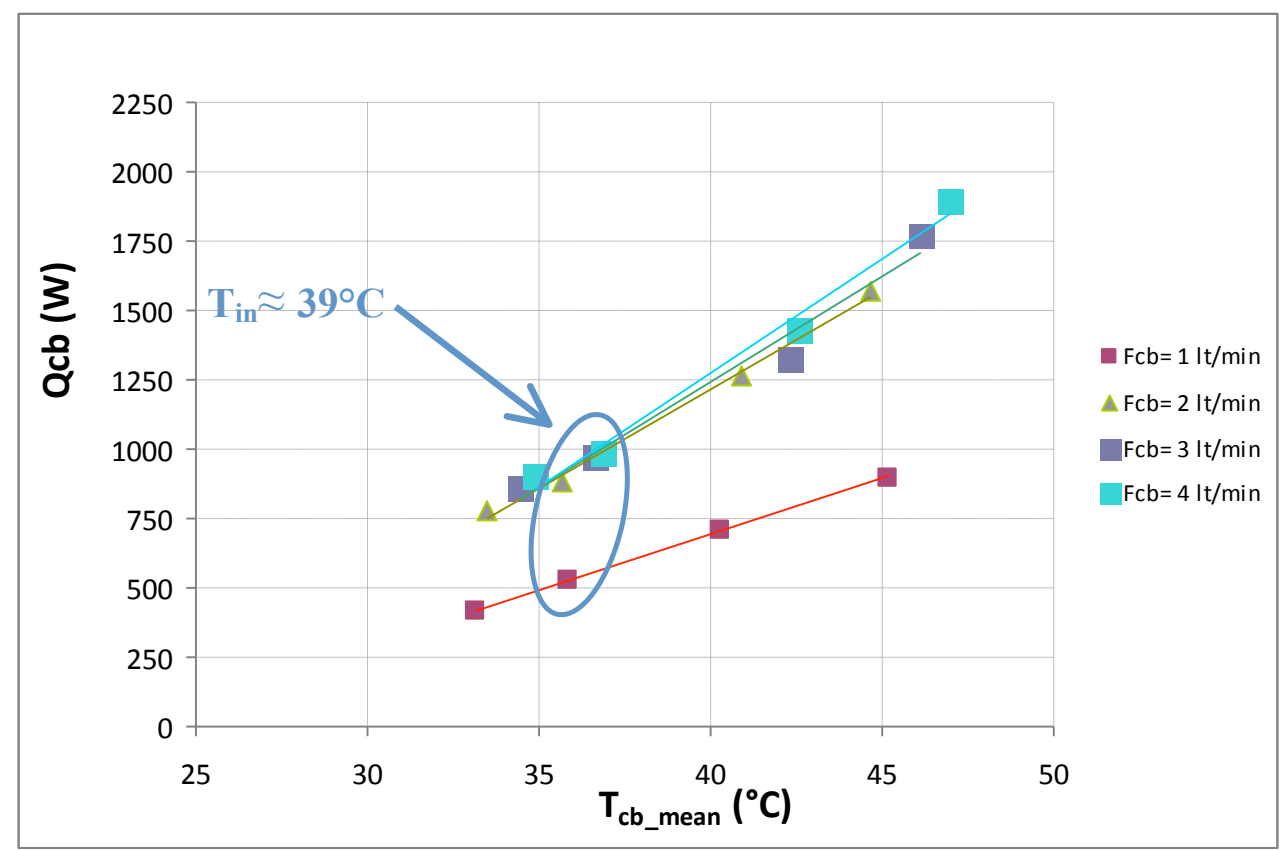

Fig.15 Heat removed from the internal stream, as a function of the average temperature of the internal stream, for different internal flow rates. $F_{c b}=1-2-3-4 \mathrm{lt} / \mathrm{min}$ and $F_{e b}=0.6 \mathrm{lt} / \mathrm{min}$.

Finally, the influence of the external flow rate can be observed comparing the two graphs, which show slightly lower values of $\mathrm{Q}_{\mathrm{cb}}$ for $\mathrm{Feb}=0.6 \mathrm{lt} / \mathrm{min}$. 


\subsection{Influence of the evaporative cooling process on the performance of the BECC device}

In order to assess the effect of the evaporative cooling phenomenon on the unit performance, some further tests were performed with and without the external stream, thus comparing the cooling efficiency of the unit as it is, with the cooling efficiency only related to the convective heat transfer from the external surface to the ambient air (i.e without any liquid stream evaporating on the external surface of the channel). Fig. 16 clearly shows how convective heat transfer contributes to the cooling performance only for $1-2{ }^{\circ} \mathrm{C}$, whereas the performance of the BECC unit achieves cooling temperatures of almost $10^{\circ} \mathrm{C}$ for the lowest flow rates and more than $6^{\circ} \mathrm{C}$ for the highest. This allows to state that convective transfer affected the cooling efficiency by less than $20 \%$ of the total cooling efficiency.

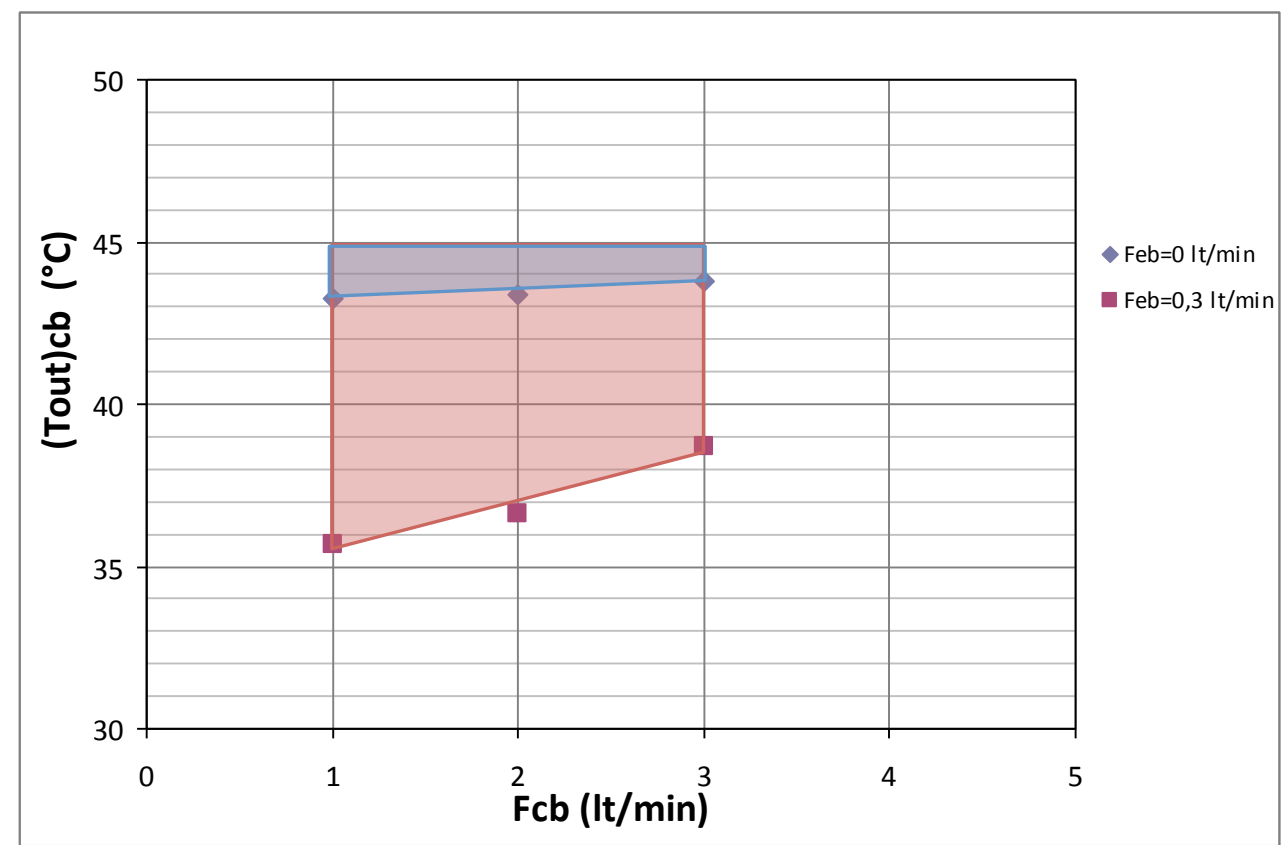

Fig.16 Comparison of the cooling efficiency as a function of internal flow rate, with and without external liquid flow. $\mathrm{T}_{\text {in }}=45^{\circ} \mathrm{C}$.

\subsection{Future developments}

Given the good performance of the unit registered during the first test runs in a quite flexible range, the BECC device shows a significant potential for future developments and applications. The next step will be related to one of the most important features of the system, i.e. the modularity. A 5 cells unit (Fig. 17) will be constructed and tested under real operating conditions and fed with real brine to assess the real performance of the system and its actual response to scaling and fouling problems. In particular, such unit will be operated within a 5 $\mathrm{m}^{3} / \mathrm{d}$ Solar Membrane Distillation plant operating on the island of Pantelleria (Italy). 


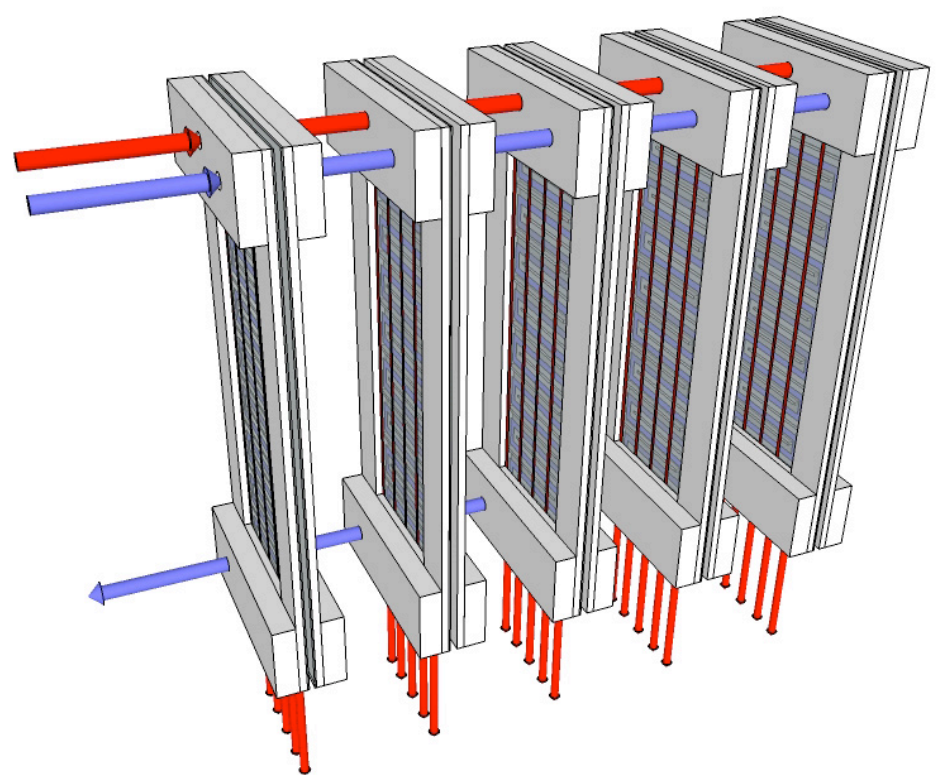

Fig. 17 A sketch of the 5 cells prototype to be constructed and tested in Pantelleria under real operating conditions.

\section{Conclusions}

The use of small desalination plants to provide fresh water in isolated areas often raises the problem of waste brine disposal, particularly when the plant is located far from the sea. In the present work a novel Brine Evaporative Cooler Concentrator (BECC, patent pending [15]) device is presented with the double aim of cooling the brine exiting from a thermal desalination plant, thus allowing the recirculation of the brine itself into the plant, and concentrating the brine to be disposed, thus reducing the volume of the liquid waste. This goal is achieved by adopting the well known evaporative cooling process, in which a stream is cooled by evaporation of a secondary liquid stream in contact with atmospheric air (moved by wind or by forced circulation), thus using the subtraction of the latent heat of evaporation of this latter to cool the first stream.

A laboratory unit has been designed, constructed and tested. The unit has got a planar geometry, is modular, can be easily assembled/disassembled for cleaning purposes and is entirely constructed with polymeric materials, thus being perfectly suitable for treating concentrated brines with high corrosion and scaling potential.

The first results have shown that a cooling of $5^{\circ} \mathrm{C}$ to $10^{\circ} \mathrm{C}$ can be easily achieved in standard conditions of air relative humidity between $40 \%$ and $70 \%$ and wind speed around $2 \mathrm{~m} / \mathrm{s}$. Such cooling has been found perfectly suitable for the recirculation of brine in small capacity Membrane Distillation or Humidification/Dehumidification units, thus indicating already a practical application of the BECC technology.

\section{Nomenclature \\ $Q \quad$ heat removed from a stream, $\mathrm{W}$; \\ $F \quad$ stream flow rate, $1 \mathrm{t} / \mathrm{min}$; \\ $C_{p} \quad$ stream specific heat, $\mathrm{J} / \mathrm{kg}^{\circ} \mathrm{C}$; \\ $T \quad$ stream temperature, ${ }^{\circ} \mathrm{C}$;}

\section{Subscripts \& Superscript}

in inlet stream; 
out outlet stream;

$c b \quad$ recirculated brine (i.e. the internal brine to be cooled);

$e b \quad$ by-pass brine (i.e. the external brine evaporating in contact with ambient air);

tot total, i.e. sum of $c d$ and $e b$;

mean average value between in and out.

\section{Acknowledgments}

This work has been carried out with the financial support of the MEDIRAS project within the EU-FP7 research programme (contract number TREN/FP7EN/218938).

The authors would like to acknowledge the help of Mr. Giovanni Genna, Mr. Leonardo Gentile and Ms. Jelena Woijack for their contribution in the experimental investigation activities.

\section{References}

1) Cipollina A,. Brucato A., Micale G., "A mathematical tool for describing the behaviour of a dense effluent discharge", Desalination and Water Treatment, Vol.2, 2009, pp.295-309.

2) Truesdal J., Mickley P.M., and Hamilton R., "Survey of membrane drinking water plant disposal methods", Desalination 102 , 1995, pp. 93-105

3) Ahrned M., Hoey D., Shayya W.H., Mahendran A., Morris R., Al-Handaly J., "Use of evaporation ponds for brine disposal in desalination plants", Desalination 130, 2000, pp. $155-168$

4) Gilron J., Folkman Y., Savliev R., Waisman M., Kedem 0., "WAIV - wind aided intensified evaporation for reduction of desalination brine volume", Desalination 158 , 2003, pp. 205-214

5) Saripallia K.P., Sharmaa M.M., Bryant S.L., "Modeling injection well performance during deep-well injection of liquid wastes", Journal of Hydrology 227 , 2000, pp. 41-55

6) Fisenko S.P., Petruchik A.I., Solodukhin A.D., "Evaporative cooling of water in a natural draft cooling tower", International Journal of Heat and Mass Transfer 45 , 2002, pp. 4683-4694

7) Kairouani L., Hassairi M., Tarek Z. , " Performance of cooling tower in south of Tunisia”, Building and Environment 39, 2004, pp. 351 - 355

8) Milosavljevic N., Heikkila P., "A comprehensive approach to cooling tower design", Applied thermal engineering 21, 2001, pp. 899-915

9) Finlaya I.C. and Harrisa D., "Evaporative cooling of tube banks. Le refroidissement de nappes de tubes par évaporation d'eau", International Journal of Refrigeration Volume 7, 1984, pp. 214-224.

10) Steeman M., Janssens A., De Paepe M., " Performance evaluation of indirect evaporative cooling using whole-building hygrothermal simulations", Applied Thermal Engineering 29, 2009, pp. 2870-2875.

11) Facao J., Oliveira A., "Heat and mass transfer correlations for the design of small indirect contact cooling towers", Applied Thermal Engineering 24, 2004, pp. 1969-1978.

12) Zalewski W., Gryglaszewski P.A., "Mathematical model of heat and mass transfer processes in evaporative fluid coolers", Chemical Engineering and Processing 36, 1997, pp. 271-280. 
13) Saman W. Y. and Alizadeh S., "Modelling and performance analysis of a cross flow type plate heat exchanger for dehumidification/cooling", Solar Energy Vol. 70, 2001, pp. 361372

14) Madhawa Hettiarachchi H.D., Golubovic M., Worek W.M., "The effect of longitudinal heat conduction in cross flow indirect evaporative air coolers", Applied Thermal Engineering 27, 2007, pp. 1841-1848.

15) Micale G., Cipollina A., Rizzuti L., Gentile L., Genna G., Glade H., Woijack J., Koschikowski J., Italian patent n. RM2010A000516, registered on the $1^{\text {st }}$ October 2010. 